\title{
An Intercultural Communication Study of Chinese and Malaysian University Students' Refusal to Invitation
}

\author{
Maryam Farnia (Corresponding author) \\ English Language Studies Section, School of Humanities \\ Universiti Sains Malaysia, Penang 11800, Malaysia \\ E-mail: mfarniair@gmail.com \\ Xiaojuan $\mathrm{Wu}$ \\ TESOL section, School of Education, Universiti Sains Malaysia \\ Penang 11800, Malaysia \\ E-mail: gogyoukenn2007@yahoo.co.jp
}

$\begin{array}{lc}\text { Received: September 12, } 2011 & \text { Accepted: October 6, } 2011 \quad \text { Published: February 1, } 2012 \\ \text { doi:10.5539/ijel.v2n1p162 } & \text { URL: http://dx.doi.org/10.5539/ijel.v2n1p162 }\end{array}$

\begin{abstract}
One of the challenges brought about by intercultural communication is the cross-cultural understanding of what is meant by what is said in another culture. Performing a given communicative act in a different cultural background than the speakers' own requires taking into consideration several issues in order not to be perceived as impolite, rude, or even offensive in the host community.

The present study aims to investigate the pragmatic behavior of refusal to invitation by Chinese international university students and Malaysian university students in Malaysia. The second aim is to seek the respondents' perception in the process of refusing an invitation regarding their cognition, language of thought, and perception of insistence after refusing an invitation. The subjects were selected from forty Chinese international students and forty Malaysian students at University Sains Malaysia, Malaysia. Data were collected through a written discourse completion task and an immediate structured post-interview.
\end{abstract}

An analysis of the data demonstrated that both Chinese and Malaysian respondents used similar type of strategies when refusing an invitation; however, they were different in terms of the number of strategies (i.e. frequency) used in each situation. It is hoped that the present research will not only make contributions to the studies of refusal behavior in the intercultural communication in general but to the pragmatic behavior of refusal to invitation between Chinese international students and Malaysian students in particular.

Keywords: Intercultural communication, Speech act of refusal to invitation, Chinese international students, Malay university students, Malaysia, Strategies

\section{Introduction}

Intercultural communication is not a new concept. There would be no need to study intercultural communication in the case in which people never come into contact with each other, and therefore, there would be no need to communicate with people who speak a different language and organize their lives according to completely different norms and values (Pinto, 2000). However, what is new about intercultural communication is the systematic study of exactly what happens when cross-cultural contacts and interactions take place- when message producer and message receiver are from different cultures (Gao, 2006).

One of the challenges brought about by intercultural communication is the understanding of speech acts cross-culturally. Speech acts or the communicative acts (e.g. thanking, apology, request) vary cross-culturally and the appropriate use of a given speech acts is subject to variation as the cultures differ. For example, in complimenting someone on her new dress, a positive acceptance of the compliment by appreciation (e.g. thank you) is common in some cultures (e.g. the United States), while rejecting the compliment (e.g. no, it is not new) 
is more appropriate in some other cultures (e.g. India). Therefore, a successful intercultural communication requires the non-native speakers' knowledge of the meaning of a particular speech act in a given cultural setting. Studies on speech acts can be divided into three categories: studies within one specific language (e.g. Koike, 1989; Turnbull and Saxton, 1997), studies between two or more languages (e.g. Chen, 1993; Lee-Wong, 1994; Fukushima, 1996; Liao and Bresnahan, 1996; Pair, 1996) and studies between languages produced by native and non-native speakers (e.g. Beebe, Takahashi, and Uliss-Weltz, 1990; Yu, 1999; Hassall, 2001; Byon, 2004, cited in Hsien and Chien, 2005).

The present research is of the second type: it examined the speech act of refusal to invitation between Chinese international students in Malaysia and Malaysian university students. Refusals have been recognized as a "major cross-cultural sticking point for many non-native speakers" (Beebe, Takahashi and Uliss-Weltz, 1990, p. 56). A refusal is a negative response given to an offer, request, invitation, etc. How to say 'no' sometimes is much more important than the answer itself since failure to refuse appropriately may lead into unintended offense or breakdown in communication. According to Al-Kahtani (2005), the speakers must be familiar with the appropriate form and its function, the speech acts and its social elements and cultural-linguistic values of each individual group. Having those skills are very important since the "inability to say 'no' clearly has led many non-native speakers to offend their interlocutors" (Ramos, 1991).

While there are great number of studies which have examined certain speech acts (e.g. request, apology), the amount of research on refusals is much more limited. Out the fifteen studies in the topic of refusals, only six included non-native speakers of English and only four of these studies examined how non-native speakers of languages other than English utilized English in making refusals (Beebe, Takahashi and Uliss-Weltz, 1990; Chen, 1995; King and Silver, 1993). Consequently, it was the lack of research on the interaction between non-native speakers of English in the context where English is used as a means of communication in particular and Chinese international university students' interaction in Malaysia with Malaysian university students in refusing an invitation in particular which has been motivated this study.

In today's increasingly connected world, it is becoming more important than ever that the language learners attain true communicative competence (Sadler and Eröz, 2001). Pragmatic failure or the "inability to understand what is meant by what is said" (Thomas, 1983) often occurs due to learners' insufficient L2 sociocultural knowledge. There are many studies on pragmatic failure of Chinese second language learners (He \& Yan, 1986; Hong, 1991; Chen, 2005; Zhang, 2005, cited in Lin, 2008). However, few studies have addressed Chinese learners of English in the target language community (Lin, 2008). The pragmatic failure not only results in miscommunication and hinders effective communication, but also leads in the misjudgment of the interlocutor $\mathrm{him} /$ herself in a cross-cultural dyad (Chen, 1996). Moreover, according to Lin (2008), among the many studies on Chinese learners of English, few have used Chinese learners of English as subjects in the target language community although many have been conducted in EFL classroom settings in China (e.g. He and Yan, 1986; Chen, 2005; Zhang, 2005). Therefore, continued research in intercultural communication will provide an improved understanding of the differences and similarities of the pragmatic behavior speakers of different languages use on a given speech act. In consequence, the aim of this study is two-fold: first, to investigate the pragmatic behavior in refusal to invitation by Chinese international university students and their Malaysian counterparts at Universiti Sains Malaysia, Malaysia and second, to seek the students' perception in the process of refusing an invitation with regard to the cognition, language of thought, and perception of insistence after refusing an invitation.

\section{Review of Literature}

The review of literature includes four sections: the first section is a brief review of learning and use of speech acts and retrospective verbal report. The second section discusses intercultural communication and elaborates on speech act of refusal to invitation.

\subsection{Learning and Use of Speech Act}

Learners utilize different strategies when producing speech acts (Félix-Brasdefer, 2008). Cohen (2005, cited in Félix-Brasdefer, 2008) suggested a classification of language-learning strategies to assist learners improve their pragmatic knowledge in a target language:

a. Cognitive strategies which help learners identify, distinguish, practice and commit material to memory. For example, in the speech act of expressions of gratitude, learners (as favor receivers) use strategies to mitigate the imposition on the speakers' shoulder and express gratitude adequately. 
b. Metacognitive strategies which include the planning, execution (e.g. checking how it is going) and the evaluation of a speech act

c. Effective strategies which regulate attitude, motivation for learning an L2 and reduce anxiety, and

d. Social strategies which include seeking opportunities to interact with native speakers and to involve in various speech act interactions.

On the other hand, language- use strategies focus on using the language that learners have learned to whatever degree in their current interlanguage (Cohen, 1996; 1998, cited in Félix-Brasdefer, 2008). These strategies are as follows:

a. Retrieval strategies which are used to retrieve the pragmalinguistics information necessary to perform a speech act, such as the use of the conditional in Spanish to express politeness (Chodorowska-Pilch, 2004)

b. Rehearsal strategies that include practicing (form-focused practice) target language structures

c. Cover strategies that include using a memorized or formulaic form that has not been fully understood in an utterance, or the use of simplification as a result of incomplete knowledge of the target language, and

d. Communication strategies which aim at conveying meaningful information or expressing an appropriate speech act response in a target language.

The proposed classification can be also used to examine the cognitive processes learners use when planning and executing refusals in a foreign language. One way to analyze cognitive processes (e.g. selection of language of thought) or learner' perceptions of sociocultural information is by means of retrospective verbal reports.

\subsection{Retrospective Verbal Reports}

Retrospective reporting is a common method of data collection in psychology and in L2 pragmatic research (Cohen, 2004; Ericson and Simon, 1993). In retrospective verbal report, data are collected immediately after completion of another task while much information is still available in short-term memory and can be directly reported or used as 'retrieval cues'. Cohen (2004) reported this technique as an effective and useful source of information in case the data are collected carefully. Verbal report can provide metalinguistic data with regard to cognitive processing (Félix-Brasdefer, 2008). This technique is used to realize what information learners is attending to while performing a task (Cohen, 1998). The purpose of using this technique in ILP research is because "one may learn what the respondents actually perceived about each situation (e.g. what they perceived about the relative role status of the interlocutors) and how their perceptions influenced their responses" (Cohen, 2004, p.321). Verbal reports used in ILP provide information on the cognitive processes involved in the production of different speech acts. Robinson (1992) examined the effect of discourse completion task and verbal reports (i.e. think aloud protocol) on the speech act of refusal among learners of English as a second language. Results showed that verbal report procedures elicit specific information about the planning processes of refusals as learners attempted to produce semantic formula, and it was concluded that verbal reports appear to be a 'practical means for both generating and investigating hypotheses about second language acquisition of pragmatic knowledge" (Robinson, 1992, p.50). In another study, Cohen and Olshtain (1993) examined the cognitive processes involved in the production of apologies, complaints and requests among EFL learners. Their findings showed that the selection of the language of thought during the planning and execution of a speech act was a complex matter the learners utilized different strategies to search for language forms, and that learners did not attend much to grammar or pronunciation. According to Felix-Bradsfer (2008), issues such as how learners' perceptions influence their understanding of politeness, their perception of pragmatic knowledge in the target language, the selection of the language of thought to deliver a given speech act (e.g. expressions of gratitude) are all areas which need to be explored.

\subsection{Intercultural Communication}

There are several definitions of the concept of intercultural communication. The word intercultural has been characterized by a certain terminological arbitrariness: intercultural, interethnic, interracial, and cross-cultural often seem to be used in free variations. In intercultural communication, the notions culture and communication are very broad and vague (Knapp and Knapp-Potthoff, 1987, p.3). They might be regarded as everything that is a consequence of culture, and everything communicates (Knapp and Knapp-Potthoff, 1987). This view is summarized in Hall's (1959) dictum "communication is culture, culture is communication" (cited in Knapp and Knapp-Potthoff, 1987, p.3). However, as Spencer-Oatey (2006) describes the phenomenon, 
"Intercultural communication is concerned with communication between people from different sociocultural groups. It focuses on the role played by cultural-level factors (in contrast to individual and universal factors), and explores their influence on the communication process" (p. 2537)

In international cross-communication, it is the learners' incompetency in interpreting and giving correct pragmatic behavior to the literal meaning rather than learners' mal- or mispronunciations or grammatical mistakes which may cause serious intercultural miscommunication. Even learners' apparent fluency or accuracy or in other words, their language proficiency does not guarantee thoroughly effective communication. In other words, the development of grammatical competence does not necessary mean a corresponding level of pragmatic competence, which might lead to pragmatic failure (Omar, 1991; Takenoya, 1995, cited in Al-Momani, 2009; Bardovi-Harlig, 1999). According to Rintell and Mitchell (1989, cited in Lin, 2008), learners' inability to understand the literal meaning and lack of knowledge of the rules of use for interpreting the words may create misunderstanding and even offense. Studies in intercultural communication may have a great impact on speakers' mutual understanding and their expectation especially in a novel cultural setting. Sometimes speaker's pragmatic incompetency leads into failure or breakdown into intercultural communication.

Pragmatic failure or "the inability to understand what is meant by what is said" (Thomas, 1983, p.91) is a new branch of pragmatics which occurs from the mistakes which fail to fulfill communication because of infelicitous style, incompatible expressions and/or improper habit (Ziran He, 1997). In such occasions, although the speakers may use grammatically correct sentences, they unconsciously violate the norms of interpersonal relationship and social norms in speech, or ignore the hearer or context (Qian, 1997). Within the field of cross-cultural pragmatics, studies of pragmatic failure have developed rapidly in the past twenty years. One of the challenges of intercultural communication is the need to create awareness about the importance of understanding speech acts cross-culturally (Palma Fathy, 2005). Therefore, intercultural communication studies on a given speech act can give insight into how interlocutors of different cultures are pragmatically different or similar as they behave in a specific situation which consequently can minimize the occurrence of pragmatic failure or breakdown in communication.

\subsection{Speech Act of Refusal}

The speech act of refusal is identified as a response to four specific speech acts: those of request, invitation, offer and suggestion (Beebe, Takahashi and Uliss-Weltz, 1990; Chen, Ye, and Zhang, 1995) rather than one which initiates this act by itself (Zhou Geyang, 2007). Refusal is characterized as an act by which a speaker refuses to engage in an action proposed by the interlocutor (Chen, Ye, and Zhang, 1995). For example, in refusing to an invitation to go out, one might say, Sorry, I have an exam tomorrow. A response to refusal can be expressed either directly, e.g. No, I can't, or indirectly. An indirect response to refusal may increase the degree of complexity, as the speaker has to choose the appropriate form or forms to soften the negative effects of a direct refusal (Felix- Brasdefer, 2008). Refusals may be mitigated by giving reasons (e.g. I have to do my assignment), expressing regret (e.g. I'm so sorry), or promising future acceptance (e.g. I hope I can make it next time).

Refusals can also be accompanied by expressing positive remarks or feelings (e.g. Congratulations on your promotion. I am very happy to hear that but...), an expression of gratitude (e.g. Thanks for your invitation), an expression of willingness (e.g. I'd love to but...). Overall, refusals are complex speech acts which require not only long sequences of negotiation and cooperative achievements, but also "face-saving manoeuvres to accommodate the noncompliant nature of the act" (Gass and Houck, 1999, p.2). According to Tanck (2002), refusal occurs "when a speaker directly or indirectly says no to a request or invitation" (p.2). Refusal is described as "a major cross-cultural 'sticking point' for many non-native speakers' (Beebe, Takahashi, and Uliss-Weltz, 1990). It is a complicated act since it is affected by several factors including gender, age, level of education, power, and social status (Fraser, 1990; Smith, 1998, cited in Wannaruk, 2008). In politeness theory, refusal is a face-threatening act since it contradicts listener/ requester / inviters' expectations and is realized through indirect strategies (Tanck, 2002). In cross-linguistic or cross-cultural communication, people are different in terms of the language they employ in each speech community. In these communities, pragmatic failure sometimes occurs when the speaker uses a face-threatening speech act (e.g. request, apology, refusal). According to Takahashi and Beebe (1987, p.133), "the inability to say 'no' clearly and politely ... has led many non-native speakers to offend their interlocutors". The speech act of refusal is a universal phenomenon. However the realization of this speech act may be culturally- specific.

\section{Methodology}

The following sub-section elaborates on the respondents chosen, instruments utilized and procedure taken in the present study. 


\subsection{Subjects}

Data were elicited from two groups of respondents: international Chinese university students and Malaysian university students studying at University Sains Malaysia, Malaysia. The data were collected outside the classrooms from volunteer participants during the second semester 2010-2011. Over one hundred questionnaires were collected. However, those questionnaires which were incomplete or did not reply based on the given instructions were discarded. Table 4.1 shows a summary of the respondents' demographic data. As the table indicates, the Chinese respondents were both male and female with ages ranging from 18 to 32 . The majority of the respondents were undergraduate students. Forty five percent of the respondents have lived in Malaysia for more than 1 year; $100 \%$ of whom hold at least one type of English language certificate, which is the requirement of enrolment at USM. Table 4.1 also demonstrates that the Malay respondents included a majority of female respondents whose ages ranged from 18 to 29 , all of whom were undergraduate students. All Malaysian respondents hold MUET (Malaysian University English Test).

\subsection{Instrument}

The data were elicited through a questionnaire followed by a structured post-interview. The questionnaire consisted of two parts: the first part of the questionnaire required respondents' biodata including age, gender, nationality, language spoken at home, level of education and program. The second part of the questionnaire was an open ended questionnaire in the form of a Discourse Completion Task (DCT) adopted from Felix-Brasdefer's (2008) study of refusal to invitation. The questionnaire included two situations occurring between a professor and a student and two classmates. The respondents were asked to read the situations and write down what they might say in refusing the interlocutor's invitation in real situations. Below is a description of the DCTs and the structured interview. The questions in the structured post-interview were also adopted and adapted from Felix-Brasdefer (2008). The questions in the interview addressed respondents' perception with regard to the cognition, language of thought, and perception of insistence in the process of refusals to an invitation.

\subsubsection{Discourse Completion Task}

The open-ended questionnaire consisted of two questions which the respondents were instructed to read and respond to each one as if they were in a real situation. In Situation \#1, the respondents had to refuse an invitation to a close friend's birthday party and the Situation $\# 2$, the respondents were required to refuse an invitation to a supervisor's invitation to dinner due to his recent academic promotion.

Situation 1: A friend invites you to his birthday party next Friday evening. You have been friends since your freshman year in college. He is inviting a selected group of friends over to his house, and you are one of them, but you can't make it. What would you tell him?

You:

Situation 2: Your supervisor at university is having a party next Saturday evening at a restaurant in town and is inviting you and few other students to celebrate his recent academic promotion at university. He invites you to celebrate this important occasion with him, but you are unable to attend. What would you tell him?

You:

\subsubsection{Coding Scheme}

Following the data collection, the utterances were codified based on a classification of refusal strategy adopted from Beebe, Takahashi, \& Uliss-Weltz (1990). This coding scheme is used extensively in most refusal studies (see appendix for more information).

From the detailed description of the possible strategies to refuse an invitation based on Beebe, Takahashi and Uliss-Weltz's coding scheme, only a total of seven strategies were elicited in both Chinese' and Malaysians' responses. However, four additional strategies in addition to Beebe et al. coding scheme were found in the responses. These included one refusal strategy type and two adjunct-type strategies. The strategy is termed as compensation whereby the speaker tries to balance a bad effect of something (e.g. the speaker invites the friend to celebrate his birthday sometime later in place of refusing him this time.). The three adjuncts elicited from the responses were alerters (sir, professor, honey, dear) and greetings (e.g. birthday greetings, congratulations).

Some examples of the elicited responses and coded based on Beebe, Takahashi, \& Uliss-Weltz (1990) are as follows:

Situation 1:

Example by Chinese responses: 
- Thank you to invite me, but there is some reasons I can't join your party. I'm sorry (gratitude + reasons + negative ability + statement of regret).

Example by Malaysians responses:

- I'm sorry; I can't come to your birthday party. I've got other important things to do; I really can't postpone it to other day. (Statement of regret + negative willing/ability + reasons).

Situation 2:

Example by Chinese responses:

- Dear sir, thank you for your invitation. I'd like to but I am sorry I can't attend. But I'll try my best to attend (Alerters + gratitude + statement of positive feelings + statement of regret + negative ability + promise of future acceptance).

Example by Malaysians responses:

- Congratulations for your promotion. Thank you for inviting me to a party, but I'm really sorry I can't come because I really have an important thing to do with my family (Greetings + gratitude+ statement of regret+ negative willing/ability+ reasons).

\subsubsection{Structured Interview}

A verbal questionnaire was conducted immediately after administering the DCTs. The respondents were asked three questions in terms of their perception and cognitive processing while refusing an invitation. The verbal report questions were adopted from Félix-Brasdefer's (2008) study of invitation to refusal. According to Felix-Brasdefer, results of these reports are instrumental in gathering relevant information about learners' cognitive processes with regard to: (1) cognition (attention to information during the planning and execution of a refusal), in particular attention to politeness, discourse, grammar and vocabulary; (2) the selection of the language of thought (English or Chinese or Malay) for conveying pragmatic intent; and (3) the perception of insistence after refusing an invitation.

\section{Data Analysis}

The data were codified based on the classification of refusal strategies adopted and adapted by Beebe, Takahashi and Uliss-Weltz (1990). Those questionnaires which were either incomplete or did not follow the given instructions were discarded. The analyses were conducted based on individual item responses on each participant's DCT. The data were then entered into SPSS software for further descriptive (i.e. frequency) and statistical analysis (i.e.independent-sample t-test).

\subsection{Situation 1}

The findings showed that expressions of excuses, reasons or explanation and statement of regret were the first and second most frequently used strategy by Chinese students in refusal to an invitation while Malay respondents used statement of regret followed by expressions of excuses, reasons or explanation as the first and second most frequently used strategies in refusal to an invitation. The findings also indicated that expressions of negative ability or willingness was the third most frequently used strategies by both Chinese and Malaysian students. As table 5.1 indicates (see the appendix), the Chinese used greetings as the fourth frequently used strategy in their responses while their Malaysia counterparts used repayment followed by greetings in the frequency pattern of strategies. The results showed that expressions of positive opinions, feelings or agreement had been the fifth frequently used strategy by both Chinese and Malaysian respondents. Moreover, the findings demonstrated that Chinese used expressions of future acceptance of invitation and expressions of gratitude more often than their Malaysians counterparts.

\subsection{Situation 2}

The findings displayed that excuses, reasons or explanation and statement of regret were the first and second most frequently used strategies by Chinese students in refusing an invitation while the frequency pattern of strategies for Malaysian students were statement of regret followed by excuses, reasons or explanations. Expressions of negative ability or willingness was the third frequency of used strategy for both Chinese and Malaysian students. Table 5.2 indicates (see the appendix) that with regard to the use of adjuncts, the Chinese respondents preferred to state their positive opinions, feelings or agreement for refusing an invitation and use expressions of gratitude and appreciation more than Malaysians did. On the other hand, Malaysian used more alerters in their responses and attempted to redress the threatening face of refusal by offering and inviting the superior with another event or gatherings. 


\subsection{Statistical Analysis}

Table 5.3 shows the findings of independent sample t-test for the responses elicited from the two respondent groups. Results of statistical analysis showed that there was a statistically significant difference in the use of statement of regret in Situation 1 between Chinese and Malaysian respondents. In other words, Malaysian respondents used significantly more statement of regret in their responses than Chinese respondents. As table 5.3 displays, there is a statistically significant difference in the use of statement of regret between Chinese and Malaysian respondents. The findings showed that Chinese students used significantly more expressions of gratitude than Malaysian respondents. In addition, there are statistical significant differences in the use of alerters and repayment strategies between Chinese and Malaysian respondents. The findings showed that Malaysians used significantly more alerters and repayment strategies in their responses than their Chinese counterparts.

With respect to the use of strategies in Situation 2, results of independent sample t-test displayed that there were statistically significant differences in the use of expressing negative ability, statement of regret, use of alerters, greetings and repayment between Chinese and Malaysian university students. The findings showed that Malaysians used these strategies more significantly than their Chinese counterparts.

\subsection{Speech Act Set}

The data were analyzed qualitatively with regard to the speech act sets in respondents' production of refusals. According to Murphy and Neu (1996), a speech act set is a combination of individual speech acts. In order to develop or achieve a communicative purpose, the speaker has to produce more than one discrete speech act. For example, in case of refusals, one might appropriately produce three speech act sets: (1) an expressions of regret, "I'm so sorry", followed by (2) a direct refusal, "I can't come to your graduation," followed by (3) an excuse, "I will be out of town on business" (Chen, 1996, cited in Tanck).

According to Olshtain (1983, cited in Murphy and Neu, 1996), some cultures preferred one or another formula, or a combination of formula to produce a speech act. For example, American English tends to express an apology which is followed by an explanation while only Hebrew speakers tended to give an explanation only. In addition, these language-specific preferences may cause a second language learner to appear inappropriate in the target language; in the previous example, Hebrew speakers who transfer this formula will undoubtedly sound rude in English (Olshtain, 1983).

The responses were analyzed to determine the speech act set of refusal to invitation by Chinese and Malaysian respondents. The following speech acts set were the most frequently used speech act set to initiate the refusing acts.

Results of the analysis show the following speech act sets for situation 1:

Situation 1:

Chinese respondents:

Statement of regret+ Negative ability/willing + Reasons

e.g. I'm sorry. I can't come to you party. I'm working on my school projects.

Statement of regret + reasons

Reasons+ statement of regret

Malaysian respondents:

Statement of regret+ Negative ability/willing + Reasons

Statement of regret + reasons

Statement of regret + positive feelings

e.g. I'm really sorry. I'd love to come, but.....

Situation 2:

Chinese respondents:

Statement of regret + alerters

e.g. I'm so sorry Prof ....

Gratitude/appreciation + negative ability/ willing 
Alerters + Statement of regret

Malaysian respondents:

Statement of regret + Negative ability/willing + Reasons

Statement of regret + Reasons

Statement of regret + alerters + negative ability/ willing + Reasons

The findings displayed that Chinese and Malaysian shared more similarities in terms of the use of speech act set in the situation of refusing an invitation to a friend; however, the frequency of use of statement of regret followed by expressions of positive feelings were higher among Malaysian respondents than their Chinese counterparts. With regard to the use of speech act set in situation 2, the findings showed that Malaysians used longer and elaborated speech act set in situation 2 than their Chinese counterparts.

\subsection{Results of Structured Interview}

A structured post-interview was conducted upon the completion of DCT. The first questions addressed the respondents' cognition when refusing an invitation. They were asked what exactly they were paying attention to when they refused the invitation in either of the situations. With regard to the situation number 1, most Chinese students reported that they were thinking of the reasons as they prepared to refuse the situation (e.g. assignment, school projects or chatting time). In addition to the reasons, how to state those reasons were also very important to them. One of their concerns was not to hurt their friends' feeling. Some of the Chinese students also reported that they did not like meeting strangers.

To Malaysian respondents, on the other hand, stating the reasons until the friend was satisfied was described as being very important. The majority of Malaysian respondents reported that they are very cautious about the arrangement of words, as well as not hurt their friend's feeling or to make him/her sad. The friend's responses and reaction were described as also being important to them. The second and third questions addressed respondents' language of thought. They were asked what language they were thinking of when refusing an invitation in Situation 1 and whether they think they should switch the language of the thought (whether they were thinking in English, Chinese or Malay) at some points during their responses. Some Chinese and Malay reported that they would think in English. However, the majority of Chinese and Malaysians reported that they would think in their first language and they would switch from either Chinese to English (for Chinese) or Malay to English (for Malaysians) when they are thinking of the responses.

To examine the respondents' pragmatic knowledge, they were asked if they had noticed any cultural differences with respect to the notion of insistence between Malaysian and Chinese people. The majority of both groups of respondents agreed that Chinese people were not more insistent on these situations than Malaysians. The respondents were also asked whether they expected their friend to insist on changing their plans and going to his party and in the case of insistence, what the speakers' feelings would be and whether insistence is culturally acceptable or rude. Though some Chinese and Malaysian respondents were expecting insistence from the friend, the majority of the respondents reported that they did not expect any insistence.

To some Chinese respondents, insistence is a sign of friendship while to some others insistence made them 'sad', 'feel sorry', or 'uncomfortable' or even 'angry'. Moreover, some Chinese found out that based upon the friend's insistence, they would slightly change their mind to go. Half of the Chinese reported the notion of insistence culturally acceptable, while the other half found insistence to be culturally or personally not acceptable. On the other hand, the majority of Malaysian respondents reported that they did not expect insistence from the friend's side and in case it occurred, it was culturally acceptable although they would feel 'sad', 'guilty', or 'pity' that they could not make it to his party. Results of the interview with regard to Situation 2 shows that for the first question, the Chinese respondents were much more concerned about the reasons and the manner in which way they would state reasons to the supervisor, as well as the supervisor's attitude about them when rejecting his invitation. On the other hand, to the majority of Malaysian respondents, it was 'arrangement of the words', 'the reasons', the 'supervisor's feelings, and attitude' about them that have been more important.

The two groups responded similarly for question number 2, 3 and 4 as in situation 1. However, in response to question 5, the majority of Chinese reported that though they did not expect insistence from the supervisor, but, in the event that the supervisor did insist, they would 'feel happy' and would think that 'they've got a place or position' with the supervisor. To some others, supervisor's insistence made them feel 'sad', 'guilty', 'sorry', and 'uncomfortable'. Unlike situation 1, the majority of Chinese found it culturally acceptable to receive insistence from a supervisor. The majority of Malaysian respondent didn't expect insistence from the supervisor and in case of receiving insistence they would feel 'bad', 'guilty as a student', 'uncomfortable'. 


\section{Discussion}

The findings display that expressions of excuses, reasons or explanation, statement of regret and expressions of negative ability or willingness were the most frequently used strategies (by different frequency sequence) for Chinese and Malaysian students in Situation \#1 and Situation \#2. The findings were in line with the findings of the previous studies with data elicited from role-play which displayed that expressions of reasons and explanations is the most frequently used strategy for expressing a refusal indirectly (Felix-Brasdefer, 2003, Garcia, 1999, Nelson, 2002, Al-Issa, 2003, Al-Eryani, 2007, Al-Kahtani, 2005). Moreover, the findings of this study were in line with the findings of refusal studies on Malaysian students (Farnia and Abdul Sattar, 2010, Abdul Sattar, Salasiah Chel Lah, and Raja Rozina, 2010) in which statement of regret followed by excuses, reasons or explanations were the most frequently used strategy among Malaysian respondents.

According to the findings, the degree of elaboration of strategies varied for each group of respondents and this could be conditioned by the students' level of grammatical competence. The analyses display that Malaysian respondents used longer and elaborated responses than their Chinese counterparts. It might lie for the fact that Chinese student' lack of control of the L2 grammar prevented them from conveying and elaborating their language compared to their Malaysian counterparts.

Another conditioning factor for the planning and execution of a refusal to an invitation was the selection of thought. The most common pattern for more than $50 \%$ of students was to start thinking in the native language (i.e. planning the refusal) and then to translate from Chinese or Malay into English (i.e. executing the refusal in English). Thus, contrary to the popular belief that learners should not consult their L1 during speech act production, the results of the present study are consistent with the ideas expressed by Cohen (1998) which demonstrated that consulting the native language may be beneficial for the following strategic purposes: (1) to chunk material into semantic clusters; (2) to help learners keep their train of thought; (3) to create a network of associations; (4) to clarify grammatical roles; and (5) to make the input more familiar and consequently more user-friendly (p.5).

According to Bardovi-Harlig (1996), one of the goals in facilitating the development of pragmatic competence to provide learners with enough input and classrooms can be the source of input especially for foreign language learners. Teaching how to communicate appropriately both pragmalinguistically (using appropriate form) and sociopragmatically (using appropriate meaning) is of great importance since native speakers often forgive linguistics errors (phonological, syntactic or lexical) but they may interpret sociolinguistic errors as learners' rudeness and impoliteness rather than as the transfer of different sociolinguistic rules (Thomas, 1983; cited in Boxer, 1996, p.128).

\section{Conclusion and Pedagogical Implication}

This study examined the perception and production of the speech act of refusal to invitation among international Chinese university students who pursue their studies in Malaysia and Malaysian university students. There have been some limitations to this study. First, length of stay in the host environment plays an important role in the development of communicative competence in language learners (see Felix-Brasdefer, 2008). In this present study, the length of stay in Malaysia varied among the international Chinese students ( 1 year to 3 years), and the effect of this variable on Chinese ESL learners was not examined. In addition, although the description of DCTs was controlled for speech act type (refusal to invitation), it is likely that some learners had never been involved in situations similar to those in the DCTs. Despite these limitations, this study, however, presents a number of insights. First, the findings display that both Chinese and Malaysian students are alike in terms of the type of strategies used to refuse an invitation. However, the students acted differently with regard to the frequency of strategies used in each DCT situation. In Situation \#1, in refusing a friend's invitation, Chinese students favored expressions of positive feelings/remarks and expressions of gratitude/ appreciation more than Malaysians which may indicate different expectations of "friends" in the two cultures. In situation of refusal to a superior, Malaysians significantly used more statement of regret in the DCT situations and expressed their negative ability to attend the event more than Chinese students.

Overall, the findings of the present study support the current research in that expressions of regret and expressions of excuses, reasons and explanations are the most frequently used strategies in refusal studies. However, English teachers should pay more attention to improve their students' pragmatic competence so as to help them avoid pragmatic failure and breakdown in communication. Teachers should train the learners with the social conventions, communicative rules and values of the target nation (Zheng and Huang, 2010). In addition, research in intercultural communication will provide an improved understanding of the differences and similarities of the pragmatic behavior of speakers of different languages and cultures. 


\section{Acknowledgment}

The original form of this paper entitled Intercultural communication: a study of Chinese International students' refusal to invitation was presented in 2010 at the IACL-18 and the 22nd North American Conference on Chinese Linguistics (NACCL-22), May 20-22th, Harvard University, United States of America.

\section{References}

Abdul Sattar, H. Q., Salasiah Che Lah \& Raja Rozina, R. S. (2010). A Study on Strategies Used in Iraqi Arabic to Refuse Suggestions. The International Journal of Language Society and Culture, (30), 81-95.

Al -Issa, A. (2003). Sciocultural transfer in L2 speech behaviors: evidence and motivating factors. International Journal of Intercultural Relations, 27, 581-601. http://dx.doi.org/10.1016/S0147-1767(03)00055-5

Al-Eryani, A. A. (2007). Refusal strategies by Yemeni EFL learners. The Asian EFL Journal Quarterly, 9(2), 19-34.

Al-Kahtani, W. (2005). Refusals realizations in three different cultures: A Speech Act Theoretically based Cross-cultural. Study Journal of King Saud University, 18, 35-57.

Al-Momani, H. (2009). Caught between two cultures: The realization of requests by Jordanian EFL learners. Unpublished doctoral dissertation. Indiana University of Pennsylvania, Indiana. PA.

Bardovi-Harlig, K. (1996). Pragmatics and language teaching: Bringing pragmatics and pedagogy together. In L. F. Bouton (Ed.), Pragmatics and language learning Vol. 7 (pp. 21-39). Urbana, IL: University of Illinois at Urbana-Champaign.

Bardovi-Harlig, K. (1999). Exploring the Interlanguage of Interlanguage Pragmatics: A Research Agenda for Acquisitional Pragmatics. Language Learning, 49(4), 677-713. http://dx.doi.org/10.1111/0023-8333.00105

Barron, A. (2003). Acquisition in Interlanguage Pragmatics: Learning how to do things with words in a study abroad context. John Benjamins Publishing Company.

Beebe, L. M., Takahashi, T. \& Uliss-Weltz, R. (1990). Pragmatic failure in ESL refusals. In C. Robin, E. S. A. Scarcella \& S. D. Krashen (Eds.), Developing communicative competence in a second language (pp. 55-73). New York: Newbury House.

Boxer, D. (1996). Ethnographic interviewing as a research tool in speech act analysis: The case of complaints. In S. M. Gass \& J. Neu (Eds.), Speech acts across cultures: challenges to communication in a second language (pp. 217-239). Berlin; London: Mouton de Gruyter.

Byon, A. S. (2004). Sociopragmatic analysis of Korean requests: pedagogical settings. Journal of Pragmatics, 39(9), 1673-1704. http://dx.doi.org/10.1016/j.pragma.2004.05.003

Chen, H. J. (1996). Cross-cultural comparison of English and Chinese metapragmatics in refusal. Indiana University. (ERIC Document Reproduction Service No. ED 408860).

Chen, J. (1995). Metapragmatic judgments on refusals; Its reliability and consistency. ERIC Documat Reproduction Service No. ED 391381.

Chen, L. X. (2005). An investigation of English pragmatic competence and its implication for teaching. Journal of Liaoning Institute of Technology, 7(2), 136-139.

Chen, R. (1993). Responding to compliments: A contrastive study of politeness strategies between American English and Chinese speakers. Journal of Pragmatics, 20(1), 49-75. http://dx.doi.org/10.1016/0378-2166(93)90106-Y

Chen, X., Ye, L. \& Zhang, Y. Y. (1995). Refusing in Chinese. In G. Kasper (Ed.), Pragmatics of Chinese as Native and Target Language (pp. 119-163). Manoa, HI: University of Hawaii Press.

Chodorowska-Pilch, M. (2004). The conditional: A grammaticalized marker of politeness in Spanish. In R. M. a. Reiter \& M. E. Placencia (Eds.), Current Trends in the Pragmatics of Spanish (pp. 57-75). Amsterdam: Benjamins.

Cohen, A. D. \& Olshtain, E. (1993). The production of speech acts by EFL learners. TESOL Quarterly, 27, 33-56. http://dx.doi.org/10.2307/3586950

Cohen, A. D. (1996). Verbal reports as a source of insights into second language learner strategies. Applied Language Learning, 7(1-2), 5-24.

Cohen, A. D. (1998). Strategies in Learning and Using a Second Language. London: Longman.

Cohen, A. D. (2004). Assessing speech acts in a second language In D. Boxer \& A. D. Cohen (Eds.), Studying Speaking to Inform Second Language Learning (pp. 302-327). Clevedon: Multilingual Matters. 
Cohen, A. D. (2005). Strategies for learning and performing L2 speech acts. Intercultural Pragmatics, 2(3), 275-301. http://dx.doi.org/10.1515/iprg.2005.2.3.275

Ericsson, K. A. \& Simon, H. S. (1993). Protocol Analysis. Verbal Reports as Data. Cambridge, MA: MIT Press (original work published 1984).

Farnia, M. \& Abdul Sattar, H. Q. (2010). Intercultural communication: Malay and Thai university students' refusal to request. Paper presented at the 4th International Mahidol Conference ( $24 \& 25 \mathrm{March})$ University Kebangsan Malaysia, Malaysia and Mahidol University, Thailand.

Felix-Brasdefer, J. C. e. (2003). Declining an invitation: A cross-cultural study of pragmatic strategies in Latin American Spanish and American English. Multilingua, 22, 225-255. http://dx.doi.org/10.1515/mult.2003.012

Felix-Brasdefer, J. C. e. (2008). Perceptions of Refusals to Invitations: Exploring the Minds of Foreign Language Learners. Language Awareness, 17(3), 195-211. http://dx.doi.org/10.1080/09658410802146818

Fraser, B. (1990). Perspectives on Politeness. Journal of Pragmatics, 4, 219-236. http://dx.doi.org/10.1016/0378-2166(90)90081-N

Fukushima, S. (1996). Request strategies in British English and Japanese. Language Sciences, 18, 671-688. http://dx.doi.org/10.1016/S0388-0001(96)00041-1

Gao, F. (2006). Language is Culture - On Intercultural Communication. Journal of Language and Linguistics, $5(1), 58-67$.

Garcia, C. (1999). The three stages of Venezuelan invitations and responses. Multilingua, 18, 391-433. http://dx.doi.org/10.1515/mult.1999.18.4.391

Gass, S. M. \& Houck, N. (1999). Interlanguage Refusals: A Cross-Cultural Study of Japanese- English. New York: Mouton de Gruyter.

Hall, E. (1959). The silent language. New York: Fawcett.

Hassall, T. (2001). Modifying requests in a second language. International Review of Applied Linguistics in Language Teaching, 39(4), 259-283. http://dx.doi.org/10.1515/iral.2001.005

He, Z. R. \& Yan, Z. (1986). The Pragmatic failure of Chinese students in communication in English: An investigation of Chinese-English pragmatic differences. Foreign Languages Teaching and Research, 3, 52-57.

He, Z. R. \& Z., Y. (1986). The Pragmatic failure of Chinese students in communication in English: An investigation of Chinese-English pragmatic differences. Foreign Languages Teaching and Research, 3, 52-57.

Hong, G. (1991). English pragmatic competence and its implication for teaching. Foreign Languages Teaching and Research, 4, Foreign Languages Teaching and Research.

Hsieh, C.-L. \& Chen, C.-Y. (2005). Teaching Strategy Use in Chinese Refusals: A Comparison of Email and Telephone Communication. Proceedings of the 17th North American Conference on Chinese Linguistics (NACCL-17). pp.128-145. Monterey, California, USA: The Defense Language Institute Foreign Language Center \& The Monterey Institute of International Studies. (NSC 93-2411-H-027-001), 128-145.

King, K. \& Silver, R. (1993). "Sticking points": Effects of instruction on NNS i-eJusal strategies. ERIC Document Reproduction Service No. ED 359774.

Knapp, K. \& Knapp-Potthoff, A. (1987). Instead of an introduction: Conceptual issues in analyzing intercultural communication. In K. Knapp, W. Enninger \& A. Knapp-Potthoff (Eds.), Analyzing Intercultural communication (pp. 1-14). Berlin; New York; Amsterdam: Mouton de Gruyter.

Koike, D. A. (1989). Requests and the role of deixis in politeness. Journal of Pragmatics, 13(2), 187-202. http://dx.doi.org/10.1016/0378-2166(89)90010-5

Lee-Wong, S. M. (1994). Imperatives in requests: direct or impolite - observations from Chinese. Pragmatics 4(4), 491-515.

Liao, C.-c. \& Bresnahan, M. I. (1996). A contrastive pragmatic study on American English and Mandarin refusal strategies. Language Sciences, 18, 703-727. http://dx.doi.org/10.1016/S0388-0001(96)00043-5

Lin, M.-X. (2008). Pragmatic Failure in Intercultural Communication and English Teaching in China. China Media Research, 4(3), 43-52.

Murphy, B. \& Neu, J. (1996). My grade's too low: The speech act set of complaining. In S. M. Gass \& J. New (Eds.), Speech acts across cultures: Challenges to communication in a second language (pp. 191-216). New York: Mouton de Gruyter. 
Nelson, G., Al Batal, M. \& EL Bakary. (2002). Directness vs. indirectness: Egyptian Arabic and US English communication style. International Journal of Intercultural Relations, 26, 39-57. http://dx.doi.org/10.1016/S0147-1767(01)00037-2

Olshtain, E. (1983). Sociocultural Competence and Language Transfer: The Case of Apology. In S. Gass \& L. Selinker (Eds.), Language Transfer in Language Learning. Rowley: Newbury House Publishers.

Omar, A. (1991). How learners greet in Kiswahili: A cross-sectional survey. Pragmatics and Language learning, 2(59-73).

Palma Fahey, M. (2005). Speech acts as intercultural danger zones: A cross-cultural comparison of the speech act of apologising in Irish and Chilean soap operas. Intercultural Communication, (8).

Pinto, D. (2000). Intercultural Communication: A Three-step Method for Dealing with Differences. Garant.

Qian, G. L. (1997). Pragmatics of Chinese culture. Beijing: Qinghua University Press.

Ramos, J. (1991). Pragmatic transfer in refusals among Peurto Rican teenagers speaking English. Unpublished D.Ed. Dissertation, Teachers college, Columbia University.

Rintell, E. \& Mitchell, C. J. (1989). Studying requests and apologies: An enquiry into method. In S. Blum-Kulka, J. House \& G. Kasper (Eds.), Cross-cultural pragmatics: Requests and apologies (pp. 248-273). Norwood, NJ: Ablex.

Robinson, M. A. (1992). Introspective methodology in interlanguage pragmatics research. In G. Kasper (Ed.), Pragmatics of Japanese as a Native and Target Language (pp. 27-82): (Second Language Teaching \& Curriculum Center Technical Report \#3). Honolulu,HI: University of Hawai'i Press.

Sadler, R. W. \& Eröz, B. (2001). "I refuse you!" An examination of English refusals by native speakers of English, Lao, and Turkish. Arizona Working Papers in SLAT, 9, 53-80.

Smith, C. (1998). Can Adults "Just Say No?”: How Gender, Status and Social Goals Affect Refusals. Unpublished doctoral dissertation. University of South Florida.

Spencer-Oatey, H. (2006). Sociolinguistics and Intercultural Communication. In U. Ammon, N. Dittmar, K. Mattheier \& P. Trudgill (Eds.), Sociolinguistics: An International Handbook of the Science of Language and Society (pp. 2537-2545): Walter de Gruyter.

Takahashi, T. \& Beebe. L. (1987). Development of pragmatic competence by Japanese Learners of English. Journal of the Japan Association of Language Learners, 8(2).

Takenoya, M. (1995). Acquisition of Pragmatic Rules: The gap between what the language textbooks present and how learners perform. In M. Haggstrom, L. Z. Morgan \& J. A. Wieczorek (Eds.), The Foreign Language Classroom: Bridging Theory and Practice (pp. 149-163). New York: Garland.

Tanck, S. (2002). Speec Act Set of Refusal and Comparison of Native and Non-Native English Speakers' Production. [Online] Available: http://www1.american.edu/tesol/wptanck.pdf (August 19th, 2009)

Thornas, J. (1983). Cross-cultural pragmatic failure. Applied Linguistics, 4, 91-112. http://dx.doi.org/10.1093/applin/4.2.91

Turnbull, W. \& Saxton, K. L. (1997). Modal expressions as facework in refusals to comply with requests: I think I should say 'no' right now. Journal of Pragmatics, 27(2), 145-181. http://dx.doi.org/10.1016/S0378-2166(96)00034-3

Wannaruk, A. (2008). Pragmatic Transfer in Thai EFL Refusals. RELC Journal, 39, 318-337. http://dx.doi.org/10.1177/0033688208096844

Yu, M.-c. (1999). Universalistic and culture-specific perspectives on variation in the acquisition of pragmatic competence in a second language. Pragmatics 9(2), 281-312.

Zhang, Q. Y. (2005). Pragmatic failure by Chinese non-English majors in College English learning. Unpublished MA dissertation. Southwest-China Normal University, Chongqing, China.

Zheng, L. \& Huang, J. (2010). A Study of Chinese EFL Learners' Pragmatic Failure and the Implications for College English Teaching. Polyglossia, 18, 41-54.

Zhou Geyang. (2007). A pilot study on refusal to suggestions in English by Japanese and Chinese EFL learners. Bulletin, Graduate School of Education. Hiroshima University, Part II, No. 56, 155-163.

Ziran He. (1997). Pragmatics and English Learning. Shanghai: Shanghai Foreign Language Education Press. 
Appendix 1: Classification of Refusal

\section{I- Direct}
A. Performative (e.g., "I refuse")
B. Non-performative statement
1. "No"
2. Negative willingness/ability ("I can't." "I won't." "I don’t think so.”)

\section{II- Indirect}
A. Statement of regret (e.g., "I'm sorry...", "I feel terrible...")
B. Wish (e.g., "I wish I could help you....")
C. Excuse, reason, explanation (e.g., "My children will be home that night."; "I have a headache.”)
D. Statement of alternative

1. I can do X instead of Y (e.g., "I'd rather do..."'I'd prefer")

2. Why don't you do X instead of Y (e.g., "Why don't you ask someone else?")

E. Set condition for future or past acceptance (e.g., "If you had asked me earlier, I would have...")

F. Promise of future acceptance (e.g., "I'll do it next time"," I promise I'll..." or "Next time I'll..."- using "will" of promise or "promise")

G. Statement of principle (e.g., "I never do business with friends.")

H. Statement of philosophy (e.g., "One can't be too careful.")

I. Attempt to dissuade interlocutor

1. Threat or statement of negative consequences to the requester

(e.g., "I won't be any fun tonight" to refuse an invitation)

2. Guilt trip (e.g., waitress to customers who want to sit a while:

"I can't make a living off people who just order coffee.")

3. Criticize the request/requester, etc. (statement of negative feeling or opinion); insult/attack (e.g., "Who do you think you are?"; "That's a terrible idea!")

4. Request for help, empathy, and assistance by dropping or holding the request.

5. Let interlocutor off the hook (e.g., "Don't worry about it." "That's okay." "You don't have to.")

6. Self-defense (e.g., "I'm trying my best." "I'm doing all I can."

J. Acceptance that functions as a refusal

1. Unspecific or indefinite reply

2. Lack of enthusiasm

K. Avoidance

1. Nonverbal

a. Silence

b. Hesitation

c. Do nothing

d. Physical departure

2. Verbal

a. Topic switch

b. Joke

c. Repetition of part of request, etc. (e.g., "Monday?")

d. Postponement (e.g., "I'll think about it.")

e. Hedging (e.g., "Gee, I don't know." "I'm not sure.")

\section{Adjuncts to refusals}

1. Statement of positive opinions/feeling or agreement ("That's a good idea..."; "I'd love to...")

2. Statement of empathy (e.g., "I realize you are in a difficult situation.")

3. Pause filler (e.g., "uhh"; "well”; "uhm”)

4. Gratitude/appreciation 
Table 4.1. Summary of demographic survey

\begin{tabular}{|c|c|c|c|c|c|}
\hline \multirow{2}{*}{ sex } & \multirow[b]{2}{*}{ Male } & \multicolumn{2}{|c|}{ Chinese respondents } & \multicolumn{2}{|c|}{ Malaysian respondents } \\
\hline & & 16 & $44.5 \%$ & 2 & $5.3 \%$ \\
\hline & Female & 20 & $55.5 \%$ & 36 & $94.7 \%$ \\
\hline \multirow[t]{3}{*}{ Age } & $18-22$ & 28 & $78 \%$ & 30 & $79.5 \%$ \\
\hline & $23-27$ & 3 & $8 \%$ & 7 & $18.5 \%$ \\
\hline & $28-32$ & 5 & $14 \%$ & 1 & $2.6 \%$ \\
\hline \multirow[t]{3}{*}{ Education } & Degree & 32 & $89 \%$ & 38 & $100 \%$ \\
\hline & Master & 3 & $8 \%$ & 0 & $0 \%$ \\
\hline & $\mathrm{PhD}$ & 1 & $3 \%$ & 0 & $0 \%$ \\
\hline \multirow{4}{*}{$\begin{array}{l}\text { Years of } \\
\text { stay in } \\
\text { Malaysia }\end{array}$} & 1 year & 12 & $33.3 \%$ & & \\
\hline & 2 years & 16 & $44.4 \%$ & & \\
\hline & 3 years & 5 & $13.9 \%$ & & \\
\hline & 4 years & 3 & $8.4 \%$ & & \\
\hline
\end{tabular}

Table 4.3. Respondents' evaluation of their language proficiency

\begin{tabular}{|l|l|r|l|r|}
\hline \multirow{2}{*}{} & \multicolumn{2}{|c|}{ Chinese respondents } & \multicolumn{2}{l|}{ Malay respondents } \\
\cline { 2 - 5 } & Frequency & Percent & Frequency & Percent \\
\hline Near native & 0 & $0 \%$ & 0 & $0 \%$ \\
\hline Very good & 0 & $0 \%$ & 2 & $5.55 \%$ \\
\hline Good & 11 & $30.6 \%$ & 16 & $44.45 \%$ \\
\hline Fair & 23 & $63.9 \%$ & 16 & $44.45 \%$ \\
\hline Poor & 2 & $5.6 \%$ & 2 & $5.55 \%$ \\
\hline
\end{tabular}

Table 5.1. Results of responses for situation 1

\begin{tabular}{|l|r|r|r|r|}
\hline & \multicolumn{2}{|l|}{ Chinese respondents } & \multicolumn{2}{l|}{ Malay respondents } \\
\hline & Frequency & Percent & Frequency & \multicolumn{1}{l|}{ Percent } \\
\hline Negative ability/ willingness & 18 & $16.50 \%$ & 26 & $19.10 \%$ \\
\hline Statement of regret & 28 & $25.70 \%$ & 35 & $25.75 \%$ \\
\hline Excuse, reason, explanation & 29 & $26.60 \%$ & 32 & $23.55 \%$ \\
\hline Promise of future acceptance & 8 & $7.35 \%$ & 22 & $16.15 \%$ \\
\hline $\begin{array}{l}\text { Statement of positive opinions/ feeling } \\
\text { or agreement }\end{array}$ & 20 & $18.35 \%$ & 20 & $14.70 \%$ \\
\hline Gratitude/appreciation & 6 & $5.50 \%$ & 1 & $0.75 \%$ \\
\hline Total & 108 & $100 \%$ & 136 & $100 \%$ \\
\hline
\end{tabular}


Table 5.2. Results of Reponses to Situation 2

\begin{tabular}{|l|r|r|r|r|}
\hline & \multicolumn{2}{|l|}{ Chinese respondents } & \multicolumn{2}{l|}{ Malay respondents } \\
\hline & Frequency & \multicolumn{1}{l|}{ Percent } & Frequency & \multicolumn{1}{l|}{ Percent } \\
\hline Negative ability/ willingness & 19 & $19.60 \%$ & 31 & $23.65 \%$ \\
\hline Statement of regret & 25 & $25.75 \%$ & 37 & $28.25 \%$ \\
\hline Excuse, reason, explanation & 26 & $26.80 \%$ & 28 & $21.35 \%$ \\
\hline Promise of future acceptance & 5 & $5.15 \%$ & 11 & $8.40 \%$ \\
\hline $\begin{array}{l}\text { Statement of positive opinions/ feeling } \\
\text { or agreement }\end{array}$ & 15 & $15.45 \%$ & 20 & $15.25 \%$ \\
\hline Gratitude/appreciation & 7 & $7.25 \%$ & 4 & $3.10 \%$ \\
\hline Total & 97 & $100 \%$ & 131 & $100 \%$ \\
\hline
\end{tabular}

Table 5.3. Results of independent t-test

\begin{tabular}{|l|r|l|r|}
\hline Situation 1 - strategies & Sig. & Situation 2 - strategies & Sig. \\
\hline Negative ability & .11 & Negative ability & $.08^{*}$ \\
\hline Statement of Regret & $.09^{*}$ & Statement of Regret & $.01^{*}$ \\
\hline Wish & .32 & Wish & -- \\
\hline Explanation & .68 & Explanation & .88 \\
\hline Future acceptance & .71 & Future acceptance & .43 \\
\hline $\begin{array}{l}\text { Statement of positive opinions/ } \\
\text { feeling or agreement }\end{array}$ & $.03^{*}$ & $\begin{array}{l}\text { Statement of positive opinions } \\
\text { /feeling or agreement }\end{array}$ & .11 \\
\hline Gratitude/ appreciation & $.04^{*}$ & Gratitude/ appreciation & .29 \\
\hline
\end{tabular}

